\title{
Supplementary Materials of
}

\section{Increased new particle yields with largely decreased probability of survival to CCN size at the summit of Mt. Tai under reduced $\mathrm{SO}_{2}$ emissions}

Yujiao Zhu ${ }^{1}$, Likun $\mathrm{Xue}^{1,2^{*}}$, Jian $\mathrm{Gao}^{3}$, Jianmin $\mathrm{Chen}^{4}$, Hongyong $\mathrm{Li}^{1}$, Yong Zhao ${ }^{5}$, Zhaoxin Guo ${ }^{5}$, Tianshu Chen ${ }^{1}$, Liang Wen ${ }^{1}$, Penggang Zheng ${ }^{1}$, Ye Shan ${ }^{1}$, Xinfeng Wang ${ }^{1}$, Tao Wang ${ }^{6}$, Xiaohong Yao ${ }^{7 *}$, Wenxing Wang ${ }^{1}$

${ }^{1}$ Environment Research Institute, Shandong University, Qingdao 266237, China

${ }^{2}$ Collaborative innovation Center for climate Change, Jiangsu Province, Nanjing, 210023, China

${ }^{3}$ Chinese Research Academy of Environmental Sciences, Beijing 100012, China

${ }^{4}$ Shanghai Key Laboratory of Atmospheric Particle Pollution and Prevention (LAP3), Department of Environmental Science \& Engineering, Fudan University, Shanghai 200433, China

${ }^{5}$ Taishan National Reference Climatological Station, Tai'an 271000, China

${ }^{6}$ Department of Civil and Environmental Engineering, Hong Kong Polytechnic University, Hong Kong, China

${ }^{7}$ Key Lab of Marine Environmental Science and Ecology, Ministry of Education, Ocean University of China, Qingdao 266100, China

Correspondence to: Likun Xue (xuelikun@sdu.edu.cn) and Xiaohong Yao (xhyao@ouc.edu.cn)

\section{List of Texts:}

Text S1: Calculations of new particle formation rate (FR), growth rate (GR), and condensation sink (CS).

\section{List of Figures:}

Figure S1: Annual changes in national $\mathrm{SO}_{2}$ emissions and national-average air pollutant concentrations of $\mathrm{SO}_{2}, \mathrm{PM}_{10}$, and $\mathrm{PM}_{2.5}$ between 2007 and 2018 (data source: http://www.stats.gov.cn/tjsj/ndsj/, http://www.mee.gov.cn/hjzl/zghjzkgb/lnzghjzkgb/).

Figure S2: Spatial heterogeneity featured with fluctuate particle number concentrations during 11:00-14:30 on October 3, 2014 NPF events.

Figure S3: Seasonal variations of particle number size distribution on NPF days in each campaign (shaded areas are quarter of the standard deviations).

Figure S4: Relationship between $\mathrm{SO}_{2}, \mathrm{H}_{2} \mathrm{SO}_{4}$ and new particle formation rate (FR), net maximum increase in the nucleation-mode particle number concentration (NMINP).

Figure S5: Relationship between GR and $\mathrm{NO}_{2}+\mathrm{O}_{3}$ during NPF events.

Figure S6: Three types of NPF events and the 24-hour air mass back trajectories during the NPF events (a,b: Type A on 21 Mar. 2018, c,d: Type b on April 7, 2018, e,f: Type c on September 29 2014. Stars at the time axis represent the end time of trajectories). 
Text S1: Calculations of new particle formation rate (FR), growth rate (GR), and condensation sink (CS)

The apparent formation rate of new particles (FR), considering the coagulation and growth losses, is calculated based on the following equation (Sihto et al., 2006; Kulmala et al., 2012; Zhu et al., 2019):

$$
\mathrm{FR}=\frac{d N_{10-25}}{d t}+\operatorname{Coag}_{10-25} \cdot N_{10-300}+\frac{G R_{10-25}}{15} \cdot N_{10-25}+S_{\text {losses }}
$$

The coagulation loss for particles $\left(\mathrm{CoagS}_{10-25} \cdot \mathrm{N}_{10-300}\right)$ was the sum of particle-particle inter- and hetero-coagulation rates. The growth loss $\left(\mathrm{GR}_{10-25} / 15 \cdot \mathrm{N}_{10-25}\right)$ is due to condensation growth out of the nucleation mode sizes during the calculation period. $\mathrm{S}_{\text {losses }}$ includes additional losses and is assumed to be zero.

The apparent growth rate (GR) of new particles was calculated by:

$$
G R=\frac{\Delta D_{\mathrm{pg}}}{\Delta t}
$$

where $\mathrm{D}_{p g}$ is the geometric median diameter of new particles fitted by the multiple log-normal distribution functions (Whitby, 1978; Zhu et al., 2014, 2019), and $\Delta \mathrm{t}$ is the duration for the growth of new particles.

The condensation sink (CS) is the loss rate of condensable vapor molecules onto the pre-existing particles, and calculated as Kulmala et al. (2001) and Dal Maso et al. (2005):

$$
C S=2 \pi D \int D_{p} \beta_{M}\left(D_{p}\right) n\left(D_{p}\right) d D_{p}=2 \pi D \sum_{i} \beta_{M i} D_{p i} N_{p_{i}}
$$

where $\mathrm{D}$ is the diffusion coefficient, $\beta_{M}$ is the transitional regime correction factor, $D_{p i}$ is the particle diameter of size class $\mathrm{i}$, and $N_{p_{i}}$ is the particle number concentration in size class $\mathrm{i}$. 


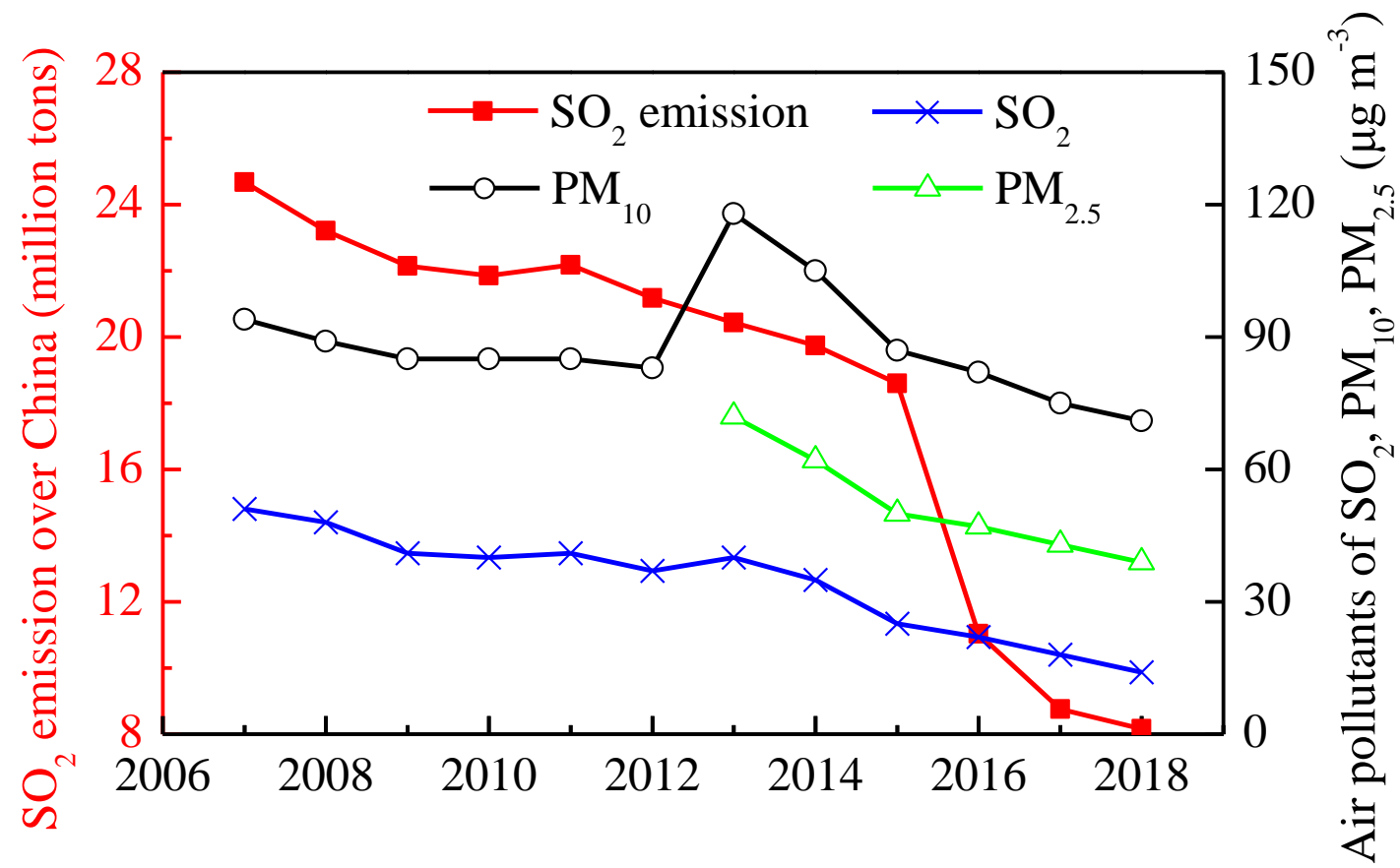

Figure S1. Annual changes in national $\mathrm{SO}_{2}$ emissions and national-average air pollutant concentrations of $\mathrm{SO}_{2}, \mathrm{PM}_{10}$, and $\mathrm{PM}_{2.5}$ between 2007 and 2018 (data source: http://www.stats.gov.cn/tjsj/ndsj/, http://www.mee.gov.cn/hjzl/zghjzkgb/lnzghjzkgb/). 


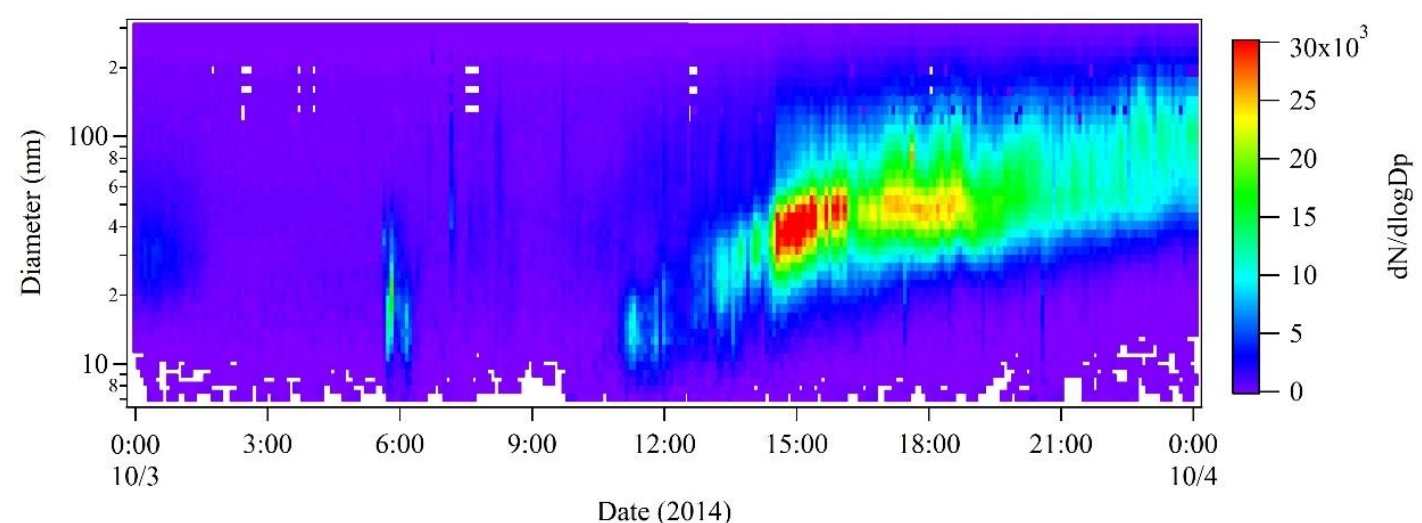

Figure S2. Spatial heterogeneity featured with fluctuate particle number concentrations during 11:00-14:30 on October 3, 2014 NPF events. 

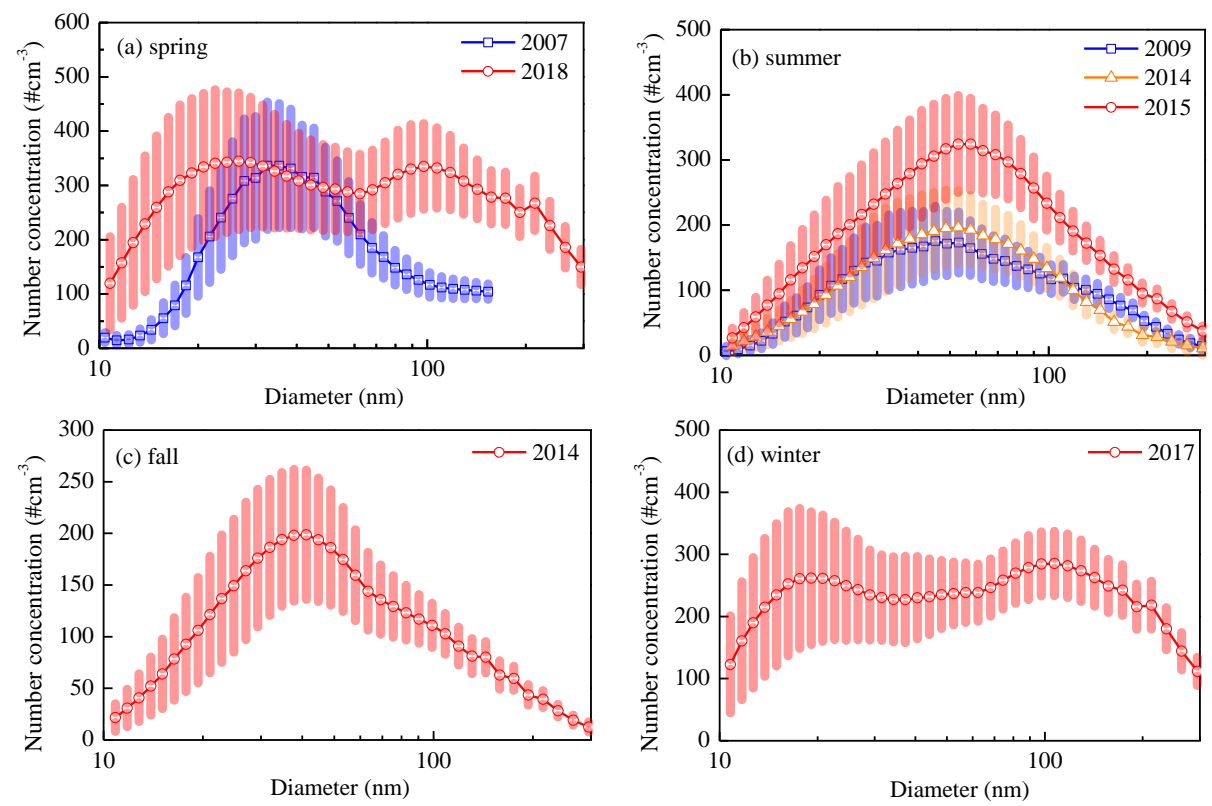

Figure S3. Particle number size distribution on NPF days in each campaign (shaded areas are quarter of the standard deviations). 

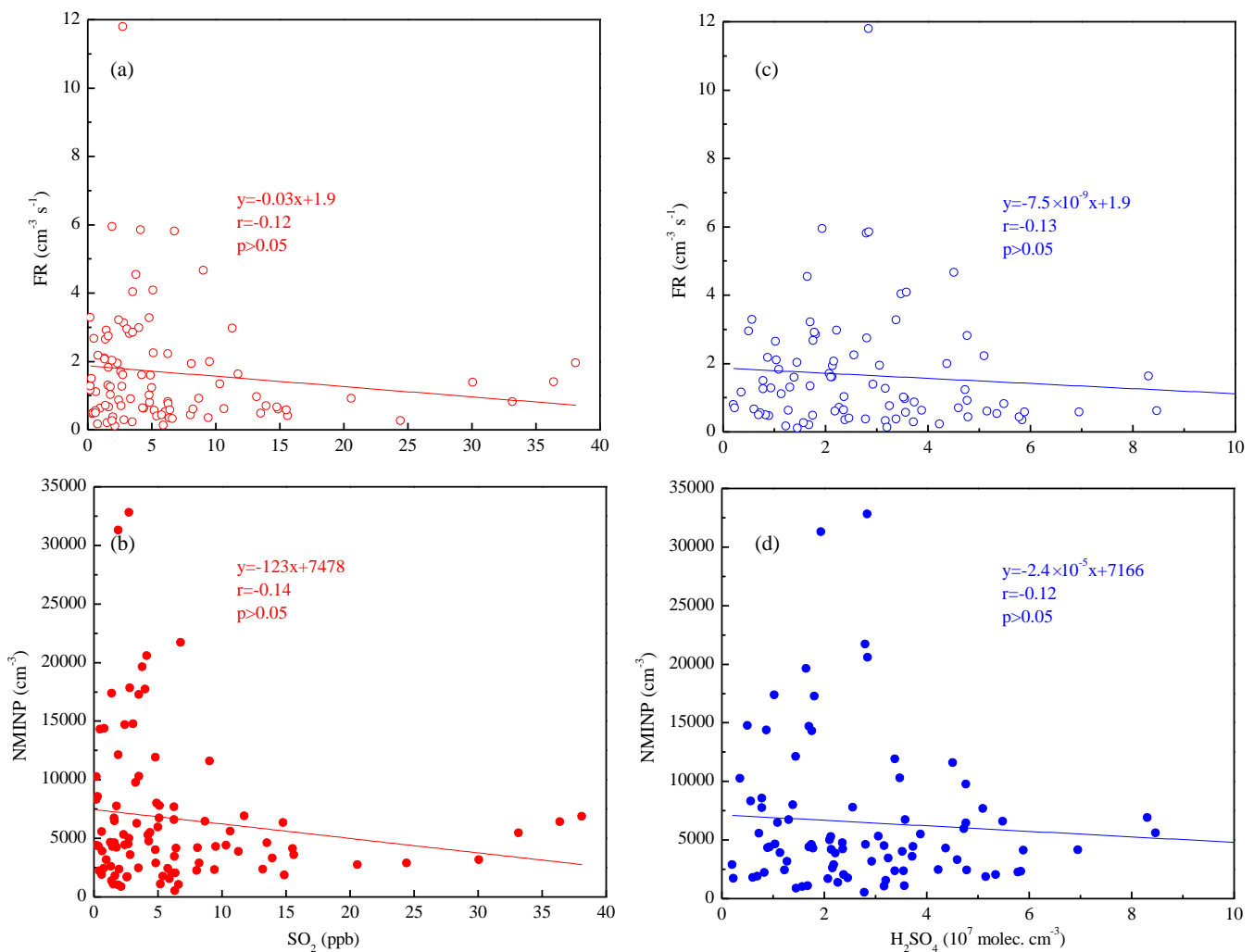

Figure S4. Relationship between $\mathrm{SO}_{2}$, calculated $\mathrm{H}_{2} \mathrm{SO}_{4}$ and new particle formation rate (FR), net maximum increase in the nucleation-mode particle number concentration (NMINP). 


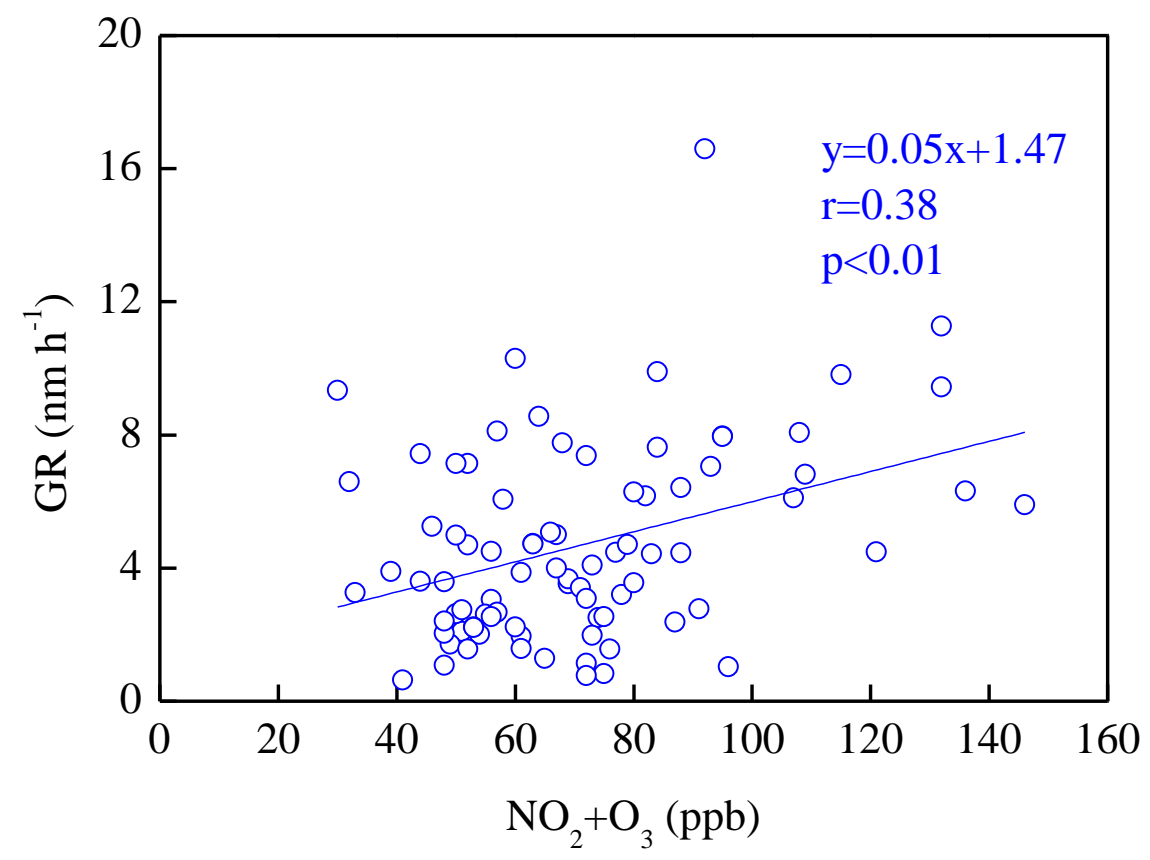

Figure S5. Relationship between GR and total oxidant $\left(\mathrm{O}_{\mathrm{x}}=\mathrm{NO}_{2}+\mathrm{O}_{3}\right)$ in the daytime NPF events. 

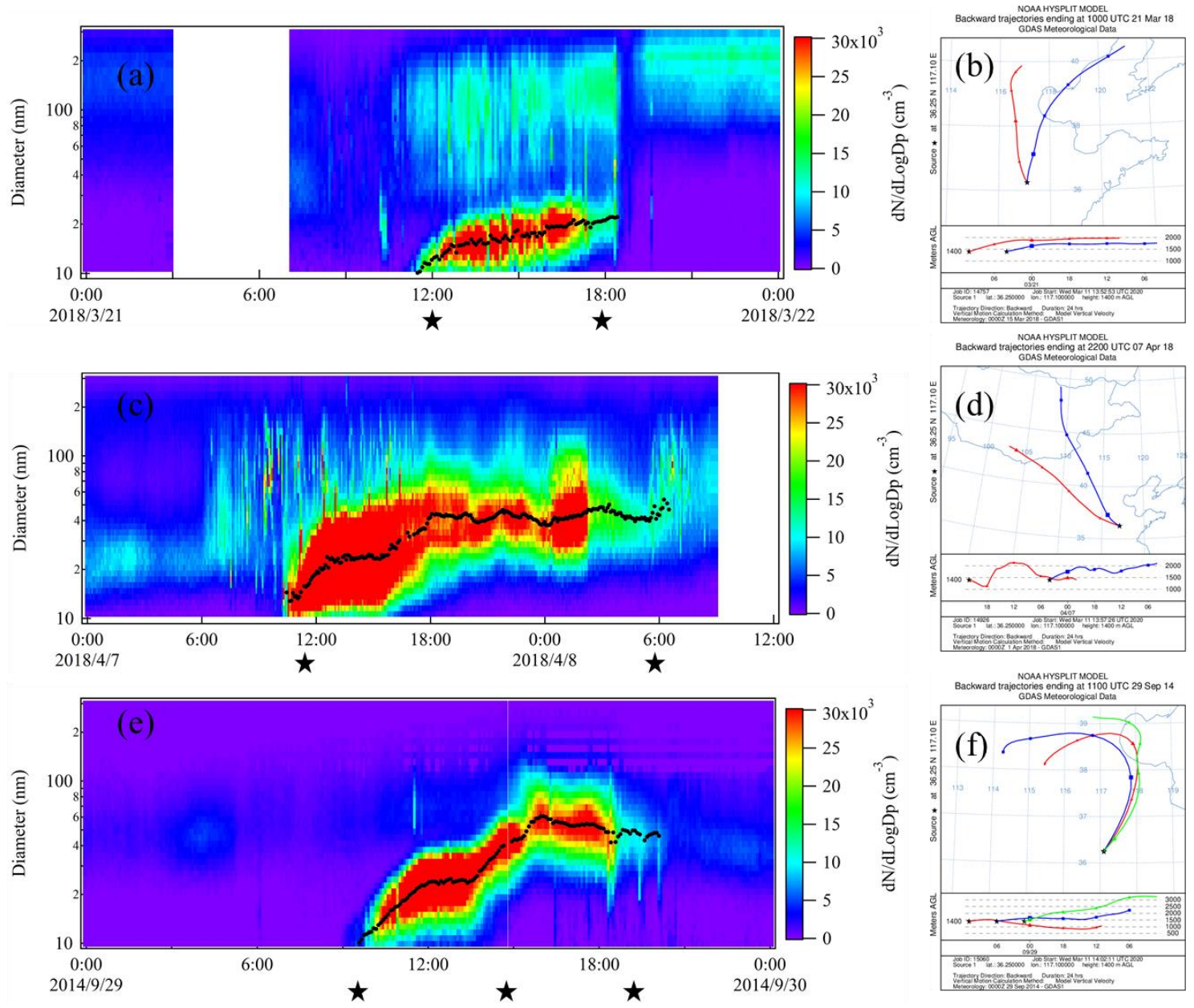

Figure S6. Three types of NPF events and the 24-hour air mass back trajectories throughout the NPF events (a,b: Type A on March 21, 2018, c,d: Type b on April 7, 2018, e,f: Type c on Sepember 29, 2014. Stars at the time axis represent the end time of trajectories). 
Reference:

Dal Maso, M., Kulmala, M., Riipinen, I., Wagner, R., Hussein, T., Aalto, P. P., and Lehtinen, K. E. J.: Formation and growth of fresh atmospheric aerosols: Eight years of aerosol size distribution data from SMEAR II, Hyytiala, Finland, Boreal Environ. Res., 10, 323-336, 2005.

Kulmala, M., Dal Maso, M., Mäkelä, J. M., Pirjola, L., Väkevä, M., Aalto, P., Miikkulainen, P., Hämeri, K., O'Dowd, C. D. On the formation, growth and composition of nucleation mode particles. Tellus B, 53(4), 479-490, 2001.

Kulmala, M., Petäjä, T., Nieminen, T., Sipilä, M., Manninen, H. E., Lehtipalo, K., Dao Maso, M., Aalto, P. P., Junninen, H., Paasonen, P., Riipinen, I., Lehtinen, K. E. J., Laaksonen, A., and Kerminen, V-M.: Measurement of the nucleation of atmospheric aerosol particles, Nat. Protoc., 7, 1651-1667, https://doi.org/10.1038/nprot.2012.091, 2012.

Sihto, S.-L., Kulmala, M., Kerminen, V.-M., Dal Maso, M., Petäjä, T., Riipinen, I., Korhonen, H., Arnold, F., Janson, R., Boy, M., Laaksonen, A., and Lehtinen, K. E. J.: Atmospheric sulphuric acid and aerosol formation: implications from atmospheric measurements for nucleation and early growth mechanisms, Atmos. Chem. Phys., 6, 4079-4091, https://doi.org/10.5194/acp-6-4079-2006, 2006.

Whitby, K. T.: The physical characteristics of sulfur aerosols, Atoms. Envrion., 12, 135-159, 1978.

Zhu, Y., Sabaliauskas, K., Liu, X., Meng, H., Gao, H., Jeong, C. H., Evans, G. J., and Yao, X.: Comparative analysis of new particle formation events in less and severely polluted urban atmosphere, Atmos. Environ., 98, 655-664, https://doi.org/10.1016/j.atmosenv.2014.09.043, 2014.

Zhu, Y., Li, K., Shen, Y., Gao, Y., Liu, X., Yu, Y., Gao, H., and Yao, X.: New particle formation in the marine atmosphere during seven cruise campaigns, Atmos. Chem. Phys., 19, 89-113, https://doi.org/10.5194/acp-19-89-2019, 2019. 